\title{
OUTROS SIGNIFICADOS E NOVAS PERSPECTIVAS: AS TRANSFORMAÇÕES DO TRABALHO NA CONTEMPORANEIDADE
}

\author{
OTHER MEANINGS AND NEW PERSPECTIVES: \\ THE TRANSFORMATION OF LABOR IN THE CONTEMPORARY
}

Fernanda Junqueira e Flávia Junqueira

\section{RESUMO}

O rápido avanço tecnológico a partir da segunda metade do século XX alavancou diversas transformações sociais, políticas e econômicas em toda a sociedade. Neste contexto, a hipótese de que os indivíduos encontrariam sentido em sua atividade laboral e desenvolveriam a totalidade de suas capacidades a partir da dominação científica da natureza vem sendo cada vez mais questionada e discutida pelas Ciências Humanas. O aumento crescente das riquezas surge como um contraponto à diminuição do trabalho no mundo. O local de trabalho e o emprego deixam de ser os principais espaços de socialização e de fontes identitárias, e o "trabalho imaterial" valoriza mais o capital humano ou do conhecimento. O presente artigo, à luz das perspectivas e ideias de autores como André Gorz, Richard Sennett e Tiziana Terrranova, tem como objetivo discutir o trabalho e o novo trabaIhador que emergem em um contexto de grandes mudanças socioeconômicas, marcado pela volatilidade de conceitos e valores.

Palavras-chave: Capitalismo. Contemporaneidade. Trabalho imaterial. Trabalhador.

\section{ABSTRACT}

The rapid technological advance since the second half of the twentieth century leveraged various social, political and economic transformations in society at large. In this context, the hypothesis that individuals find meaning in their work activities and develop all their 
capabilities from the scientific domination of nature is being increasingly questioned and discussed by the Human Sciences. The increasing amount of wealth emerges as a counterpoint to the decrease of work in the world. The workplace and employment are no longer the main areas of socialization and sources of identity and "immaterial labor" value more human or knowledge capital. This article, in light of the perspectives and ideas of authors such as Andre Gorz, Richard Sennett and Tiziana Terrranova, aims to discuss the work and the new worker emerging in a context of major socioeconomic changes, marked by volatility of concepts and values.

Keywords: Capitalism. Contemporary. Immaterial labor. Worker.

\section{INTRODUÇÃO - FLEXIBILIZAÇÃO DO TRABALHO}

A ideia de que a contemporaneidade caminha em direção à "sociedade de informação" é largamente discutida e disseminada pelas Ciências Humanas e pela opinião pública em geral. Vivemos uma época de rápidas mudanças, que geram profundas transformações, acompanhadas pela disseminação fugaz de novas tecnologias da informação e da comunicação. Talvez estejamos observando o surgimento de uma nova etapa da sociedade industrial, vivenciando uma Terceira Revolução Industrial ou, ainda, uma verdadeira Revolução Tecnológica. Nesse sentido, o trabalho, considerado cerne de nossa existência individual e social, é um dos elementos que mais se modifica em consequência das alterações societais.

Muitos são os autores que discutem as mutações pelas quais passam o modo de produção capitalista e a sociedade como um todo. O mercado global e o uso de novas tecnologias aparecem como as principais características distintivas de nossa época. Outras dimensões dessas mudanças, como as novas maneiras de organizar o tempo, sobretudo o tempo de trabalho, são debatidas por autores como David Harvey (1992) e Richard Sennett (2008).

Harvey (1992, p. 208) explica que o conceito fundamental do "preço do tempo" surgiu da exploração do espaço pelo mercador medieval, ou seja, foi o tempo de deslocamento espacial que levou o mercador a vincular os preços ao tempo de trabalho. Para o autor, "cada modo distinto de produção ou formação social incorpora um agregado particular de práticas e conceitos do tempo e do espaço" (HARVEY, 1992, p. 189). Ele afirma que a sociedade moderna entrecruzou diferentes sentidos de tempo, assim como o espaço se tornou também dissoluto diante de possibilidades como o telégrafo e o rádio, por exemplo.

Harvey defende que a manutenção do poder político depende dos significados atribuídos ao dinheiro, ao tempo e ao espaço, o que nos leva a compreender a reestruturação do mercado de trabalho nas décadas de 1970 e 1980. Nesse período, houve uma profunda recessão, exacerbada pelo petróleo, que levou problemas ao compromisso fordista. Além disso, foi quando as tecnologias da informação deram grande salto, levando a implicações que abalariam não só o sistema capitalista como também o estatismo, que era mais forte naquele período (CASTELLS, 1999, p. 32). Este processo tornou o mercado mais volátil e, consequentemente, os contratos de trabalho mais flexíveis. Segundo Harvey (1992, p. 143), o emprego regular perde, cada vez mais, espaço para o trabalho em tempo parcial, temporário ou subcontratado. $\mathrm{O}$ autor ressalta, porém, que nem sempre os trabalhadores têm consciência dos prejuízos decorrentes dessa organização flexível do emprego: 
Esses arranjos de emprego flexíveis não criam por si mesmos uma insatisfação trabalhista forte, visto que a flexibilidade pode às vezes ser mutuamente benéfica. Mas os efeitos agregados, quando se consideram a cobertura de seguro, os direitos de pensão, os níveis salariais e a segurança no emprego, de modo algum parecem positivos do ponto de vista da população trabalhadora como um todo. (HARVEY, 1992, p. 144).

Harvey segue explicando que o tempo de produção associado ao tempo de circulação da troca gera o "tempo de giro do capital". O grande esforço do capitalismo concentra-se em reduzir este tempo de giro para acelerar os processos sociais - as relações de produção, experiência e poder. Este objetivo depende de diferentes fatores desde a produção até a mobilização para o consumo, e, neste contexto, a flexibilidade dos trabalhadores tornase fundamental para seu alcance. $O$ autor sustenta que tais evidências influenciaram na superação do fordismo:

\footnotetext{
Os trabalhadores, em vez de adquirirem uma habilidade para toda a vida, podem esperar ao menos um surto, senão muitos, de desabilitação e reabilitação no curso da vida. A destruição e reconstrução acelerada das habilidades dos trabalhadores foram uma característica central da passagem do fordismo para os modos flexíveis de acumulação. (HARVEY, 1992, p. 210).
}

Neste contexto de flexibilização do trabalho e do trabalhador, Sennett (2008) afirma que o novo capitalismo, marcado pelo mercado global e o uso indiscriminado de novas tecnologias, tornaram a vida das pessoas mais dinâmicas, obrigando-as, consequentemente, a se prepararem para mudanças, incluindo frequentes trocas de emprego. O mundo é agora mais ágil e a troca de atividade ou mesmo de carreira são cada vez mais comuns. Ao mesmo tempo em que observamos uma maior flexibilidade e abertura do sistema, percebemos também alguns de seus efeitos indesejados. Como ressalta Sennett (2008), o medo de perder o controle da própria vida em razão das crescentes forças mercadológicas se tornou algo constante entre os indivíduos. As empresas se caracterizam pelo afrouxamento dos elos sociais, e os contratos trabalhistas passaram a ser de curto prazo. Há uma falta de perspectiva de compromisso duradouro com as organizações, gerando instabilidade e falta de lealdade institucional. Os empregados tendem a ficar "negociáveis" assim que percebem que não podem traçar uma trajetória dentro da organização onde trabalham e, principalmente, quando observam que não têm em quem confiar. O lema "não há longo prazo", proferido pela cultura pós-moderna ou contemporânea, como bem destaca Sennett (2008, p. 24), "corrói a confiança, a lealdade e o compromisso mútuo". Este princípio imediatista faz com que os empregos sejam substituídos por projetos e contratos temporários de trabaIho e com que a previsibilidade das relações diminua cada vez mais.

As modificações nas relações de trabalho afetam, sobretudo, a dinâmica social. A produção de conhecimento e as conquistas tecnológicas influenciam o mercado, exigindo um profissional que se atualize constantemente e que se aproprie da tecnologia a seu serviço. $O$ aumento do volume de atividades, no entanto, não representa a elevação de salários e benefícios. Líderes e gerentes de grandes empresas preocupam-se pouco com as consequências econômicas e pessoais dessas mudanças ou as encobrem com ações para 
uma melhoria na qualidade de vida dos seus funcionários. Essas práticas são comumente denominadas por motivacionais e incluem cursos, dinâmicas interacionais, ginástica laboral, dentre outras que procuram melhorar a convivência e mascarar os conflitos e contraposições existentes nas diferentes relações. Os empregados das organizações são nomeados por colaboradores na tentativa de obscurecer a exclusão e exploração presentes nas atividades trabalhistas, fazendo-os crer que ao serem classificados por esta nova terminologia poderão usufruir e participar mais das decisões empresariais. Ideologicamente estes termos e ideias a eles corelacionados têm sido utilizados de forma instrumental para mitigar as relações de poder existentes entre os trabalhadores e os grupos dominantes.

\section{NOVO CAPITALISMO E O TRABALHO IMATERIAL}

As presentes transformações do capitalismo na atualidade apontam para uma maior abertura e flexibilização econômicas. De acordo com Sennett (2008), o termo "capitalismo flexível" representa um sistema em que as formas rígidas e burocráticas dão lugar à agilidade, fluidez e transformações societais. Em consequência dessa flexibilidade, observamos um indivíduo em constante desenvolvimento, diferente do trabalhador fordista do século XX, cujas experiências laborais possibilitavam uma construção linear de vida. $\mathrm{Na}$ contemporaneidade, o aumento das incertezas, das mudanças frequentes de emprego e do afrouxamento dos laços afetivos dificultam a previsibilidade de um futuro estável.

Os teóricos pós-fordistas e pós-industriais, como Manuel Castells (1999), dissertam acerca dessa "nova economia", destacando a dominação do trabalho degradado pelo avanço tecnocientífico. O otimismo do autor se consubstancia na superação do trabalho burocrático, rotineiro e disciplinar da fábrica taylorista e fordista pela criatividade das atividades complexas emergentes das inovações tecnológicas.

A "sociedade em rede", descrita por Castells (1999), é comumente utilizada para descrever a estrutura social inovadora surgida a partir de um novo desenvolvimento moldado pela reestruturação do modo capitalista de produção, o informacionalismo. O modo de desenvolvimento informacional, para o autor, caracteriza-se pela geração de conhecimento, enquanto forma de processamento de informação, como principal fonte de produtividade, diferente do modo industrial de desenvolvimento cuja produtividade seria estimulada essencialmente pela introdução de novas fontes de energia.

Castells postula que o funcionamento da sociedade pode ser equiparado a uma rede que irradia poder e possibilita novas interações e relações sociais. A rede poderia ser caracterizada como a estrutura social determinante, cuja influência mais visível seria observada nos modelos organizacionais das empresas. Essas organizações teriam superado o padrão das burocracias verticalizadas e adotado um padrão relacional horizontal, cujas prioridades centrar-se-iam nos processos, nas atividades em equipe e na medida pela satisfação do cliente. Nas palavras do autor:

Uma estrutura social com base em redes é um sistema aberto altamente dinâmico suscetível de inovação sem ameaças ao seu equilíbrio. Redes são instrumentos apropriados para: a economia capitalista baseada na inovação, globalização e concentração descentralizada; para o trabaIho, trabalhadores e empresas voltadas para a flexibilidade e adaptabilidade; [...] e para uma organização social que vise a suplantação do espaço e da invalidação do tempo. (CASTELLS, 1999, p. 498). 
Assim como para Harvey, a passagem da década de 1970 para 1980 foi, para Castells (1999, p. 32), o período no qual o capitalismo passou por uma reestruturação em seu processo de produção. A nova forma social que o autor vislumbra sob tais transformações é a de uma sociedade globalizada, altamente tecnizada, com ênfase na utilização intensiva do conhecimento através das inovações tecnológicas oferecidas pela microeletrônica, pela informática e pelas novas tecnologias de comunicação. Neste aspecto, o autor também considera que o trabalho ganha novos sentidos ao afirmar que:

a mão-de-obra está desagregada no desempenho e reintegrada no resultado através de uma multiplicidade de tarefas interconectadas em diferentes locais, introduzindo uma nova divisão de trabalho mais baseada nos atributos/capacidades de cada trabalhador que na organização da tarefa. (CASTELLS, 1999, p. 499).

As discussões sobre o trabalho propostas por André Gorz $(2005,2007)$ ampliam o escopo de análise das transformações sociais na medida em que o toma como foco central, inserido num sistema mais amplo e abrangente, que possibilita compreender suas "metamorfoses". O autor debruça-se sobre a problemática do desemprego, sobre a precarização do mundo do trabalho e o impacto das novas tecnologias sobre a produção, destacando a reorganização e a posição dos trabalhadores em relação aos empregos existentes.

O trabalho na visão de Gorz (2007), tal como o entendemos hoje, deve sua natureza, suas funções e seus modos de organização ao capitalismo. As transformações que delimitam a noção contemporânea de trabalho encontram-se atreladas às dinâmicas do sistema capitalista e à sua forma de manter o controle sobre os trabalhadores. Em O imaterial, Gorz (2005) afirma que passamos por um momento no qual o capitalismo moderno é superado cada vez mais rapidamente pelo pós-moderno, que valoriza um capital chamado imaterial, humano ou do conhecimento. Neste sentido o trabalho ganha diferentes formas de valorização.

O processo de automação ocorrido nas fábricas e o grande aumento repentino e inesperado de aplicações tecnológicas transformaram os processos de produção e distribuição, impelindo a criação e circulação de novos produtos e alterando o acúmulo de riquezas e poder. A possibilidade de produzir mais em menos tempo e com menos trabalho despendido modificou as formas de conceber a importância da atividade laboral na sociedade.

Gorz chama o novo trabalho de imaterial e o diferencia do conceito tradicional principalmente por sua impossibilidade de ser valorizado em unidades de produto por unidade de tempo, ou seja, nele estes padrões clássicos de medida não podem ser aplicados. Como consequência, os trabalhadores também ganham novas qualidades, impossíveis de quantificar, formalizar e objetivar. Nas palavras do autor, o que conta no trabalhador "são as qualidades de comportamento, as qualidades expressivas e imaginativas, o envolvimento pessoal na tarefa a desenvolver e completar". (GORZ, 2005, p.17). Em outras palavras, toda a bagagem cultural adquirida ao longo da vida em esportes, atividades lúdicas e em equipe contribuem para a capacidade de cooperação, de coordenação e organização, aptidões em voga na economia pós-industrial. 
O trabalho, na atualidade, exige funções cognitivas mais complexas como atenção, criatividade, tomada de decisão e planejamento. O trabalho mecânico vai sendo substituído por atividades mais abstratas.

\section{TRABALHADORES DO IMATERIAL}

É interessante observarmos as transformações pelas quais passaram a divisão do trabalho e a distribuição de tarefas no seu interior. Passamos das tarefas repetitivas aos processos integrados e interativos, assegurados pela informatização e tecnologia. As atividades dos funcionários tornam-se indiretas, controladas por modelos tecnológicos de gestão. Suas habilidades, competências e conhecimento não incidem diretamente sobre a materialidade do trabalho, mas sim sobre a decodificação de dados, informações e símbolos. Como afirma Gorz (2007, p. 84), os trabalhadores

jamais intervêm no produto ou no semiproduto, isto é, no material; intervêm apenas nas máquinas que trabalham o material. Não são especialistas de um produto; são especialistas da reparação, regulação, da programação de um certo tipo de máquina.

A materialidade da produção torna-se invisível diante dos olhos do trabalhador que se comunica através de símbolos numéricos que surgem na tela de seu computador. A atividade intelectual se sobrepõe a todas as demais e pouco do que foi produzido durante uma jornada de trabalho é visível e/ou sensível.

A tecnização pode economizar tempo e trabalho humano, mas separa o produtor do produto, não permitindo que ele reconheça a finalidade daquilo que faz. Existe para que os funcionários produzam cada vez mais e melhor em menos tempo. Esta economia de tempo e trabalho instaura uma grande contradição na sociedade atual: não é possível pautar nossa existência em torno das atividade trabalhistas em um contexto que prioriza sua economia. Nas palavras de Gorz (2007, p. 93): "um trabalho que tem por efeito e finalidade fazer economizar trabalho, não pode, ao mesmo tempo, glorificar o trabalho como fonte essencial da identidade e do desenvolvimento pessoais". A reabilitação da ética do trabalho não é possível numa sociedade onde não há emprego constante para todos. A atividade laboral só adquiriria sentido caso ampliasse o campo das atividades não profissionais em que o homem pudesse preencher a sua vida.

Em sua obra Crítica da razão econômica, Gorz (2007) alerta que é preciso escamotear o fato de que há um número crescente de desempregados e empregos precários e mascarar a prerrogativa de que a sociedade do trabalho está chegando ao fim.

A sociedade do trabalho, portanto, caducou: o trabalho não pode mais servir de fundamento à integração social. Para mascarar esses fatos, é preciso contudo encontrar outras explicações à ascensão do desemprego e dos empregos precários. Então se dirá que desempregados e trabalhadores em situação precária de fato não procuram trabalho, que 
não têm aptidões profissionais suficientes e são levados à preguiça pelas excessivamente generosas indenizações de desemprego, etc. (GORZ, 2007, p. 75).

Na obra $O$ imaterial, porém, o autor argumenta que o desemprego encontra-se em transformação juntamente com o regime salarial. $O$ discurso capitalista passa a ser de que o desemprego serve como um momento para o trabalhador restaurar-se enquanto tal até que se torne capaz de suprir as demandas do mercado novamente. Em outras palavras, "se ainda existem desempregados, isso é sinal de que sua 'empregabilidade' está em falta" (GORZ, 2005, p.26) e o que antes era indenização de desemprego torna-se indenização de procura de emprego.

Gorz discute a "contaminação" da vida pelo processo de racionalização econômica a partir da submissão dos trabalhadores à esta razão que os torna cúmplices de seus patrões e os prende ao trabalho. De acordo com o autor, o trabalho imaterial depende desta subsunção da vida sob o trabalho e ela é conseguida pelo discurso da "motivação". A disposição do trabalhador deve ser a mesma para as atividades pessoais e para o trabalho e, dessa maneira, toma corpo uma nova forma de "servidão voluntária", ou seja, no momento em que o empenho do trabalhador é mais facilmente reconhecido a partir de suas atividades extraprofissionais, ele se esforçará para demonstrar que vale mais do que realiza profissionalmente investindo sua dignidade no exercício gratuito, fora do trabalho. (GORZ, 2005).

O mercado privilegia o profissional criativo que procura solucionar problemas diversos ainda que a sua organização não Ihe forneça os subsídios necessários. Este autoempreendimento torna-se discurso padrão das empresas e recrutadores. $O$ trabalhador, dentro desta perspectiva, teria autonomia para dirigir suas ações com o objetivo de atingir os resultados esperados. O mais importante é alcançar as metas determinadas pela organização e satisfazer os anseios dos clientes.

Os esforços desempenhados para incutir a razão econômica concentram-se no discurso de unificação pessoa-empresa, no qual os limites entre sujeito e organização, força de trabalho e capital são abolidos. A "produção de si" do trabalhador transforma sua força de trabalho em um capital fixo da empresa que deve ser continuamente reproduzido, modernizado, alargado e valorizado (GORZ, 2005, p. 23). Neste sentido, seus funcionários são convidados a empreenderem suas atividades, assumindo seus riscos e soluções pró-ativas.

A crítica elaborada por Gorz centra-se na profusão destes discursos dominantes, embora ele reconheça sua amplitude dentro do sistema capitalista. Só o rompimento com esta razão econômica, centrada numa estratégia de redistribuição da riqueza produzida expressa na redução da jornada de trabalho e na instituição de uma "renda de cidadania" - permitiria a construção de um caminho libertador (GORZ, 2007, p. 76-77).

A "renda de cidadania" foi mais tarde chamada de "renda de existência" (2005), em um contexto no qual Gorz (2005, p. 26) a coloca como reivindicação para que o trabalhador possa "desenvolver atividades independentes cujo valor social e/ou cultural não pode ser medido pela sua rentabilidade, nem depende dela". O autor atenta, porém, para a dupla interpretação que a "renda de existência" pode despertar. A primeira seria uma maneira de esquivar a vida ao imaginário comercial e ao trabalho total, enquanto a segunda tem a remuneração como necessária e decisiva para a contribuição da produtividade do trabalho. Gorz critica esta segunda concepção, alertando para o fato de que o processo de produção 
capitalista se aproveita de qualquer capacidade e competência desenvolvidas durante a vida. Neste sentido, utilizar a remuneração como forma de aumentar a produtividade por meio do capital imaterial seria considerar que "a vida inteira se tornou produtiva como produção de capital humano fixo. Toda a produção de si é assim rebaixada a trabalho econômico". (GORZ, 2005, p. 27).

\section{FREE LABOR}

Uma diferente questão da sociedade pós-industrial que se aproxima do que foi aqui apresentado seria o trabalho free, ou free labor, discutido por Tiziana Terranova (2003). Para a autora, este trabalho é exclusivo da economia pós-industrial à qual ela chama também de economia digital. Segundo Terranova, este termo surgiu para explicar a relação entre a economia cultural pós-moderna (mídia, universidade, artes) e a indústria de informação (complexo de informação e comunicação). A autora debate em seu texto a produção de conteúdo na Internet por seus usuários como um trabalho free, ou seja, gratuito, voluntário, e de que forma é agregado valor a este conteúdo. Não está no mérito deste trabalho aprofundar a questão da valorização do conteúdo da Internet, mas interessa-nos a motivação do usuário para continuar a produzi-lo voluntariamente.

De volta à discussão desenvolvida acima com Gorz, a razão econômica incutida em nossa mentalidade leva-nos a uma "servidão voluntária". A "produção de si", nas circunstâncias atuais, ganha proporção e torna-se um hábito socialmente formado. Como coloca Terranova (2003), a Internet possibilita a produção de conteúdo por qualquer usuário, mas não exige esta postura. Por que então há uma crescente produção free? Chegamos ao ponto de interseção de ambos os autores: o que Gorz identificou como maneira de suplantar o trabalho sobre a vida, Terranova reconhece como um desejo de produção cultural afetiva, já socialmente convencionado. Os produtores de conteúdo são chamados de NetSlaves por Terranova (2003), que observa que eles "não são simplesmente uma forma de trabalho típica da internet; eles também incorporam uma complexa relação de trabalho que é difundida nas sociedades capitalistas". ${ }^{1}$ Sobre o trabalho imaterial, ela se respalda em Maurizio Lazzarato, para afirmar que ele é "uma virtualidade (uma capacidade indeterminada) que pertence à produção subjetiva pós-industrial como um todo". ${ }^{2}$

A volatilidade do trabalho leva o funcionário a tentar afirmar todo o tempo suas qualidades criativas, suas redes de relacionamento e sua consciência coletiva; neste sentido gerar conteúdo para a Internet seria uma forma de mostrar disposição e engajamento por uma causa.

Esta virtualidade do processo de trabalho, porém, traz sérias consequências para o trabalhador. De acordo com Gorz (2007, p.71), a substituição do trabalho humano pela máquina diminui o número de funcionários nas empresas, precariza ainda mais os empregos, desqualifica suas atividades e deixa insegura uma grande massa de trabalhadores. Como consequência, observamos a dissolução das solidariedades tradicionais, dos contornos

\footnotetext{
${ }^{1}$ No original: The NetSlaves are not simply a typical form of labor on the Internet; they also embody a complex relation to labor that is widespread in late capitalist societies.

2 No original: immaterial labor is a virtuality (an undetermined capacity) that belongs to the postindustrial productive subjectivity as a whole.
} 
demarcados entre as classes, a desintegração dos laços sociais e a promoção da individualização.

O surgimento de um novo tipo de trabalhador superqualificado, capaz de acompanhar as demandas e evoluções técnicas respalda a criação ideológica empresarial que auxilia no processo de desintegração da classe operária, do movimento sindical e da solidariedade social existente. Gorz afirma que a reapropriação dos valores da utopia do trabaIho - como domínio dos meios de produção, desenvolvimento pleno das capacidades individuais e valorização do ofício - repousa sobre um cálculo racional para separar essa elite de sua classe de origem e das organizações de classe.

$\mathrm{Na}$ visão do autor, o ressurgimento das utopias humanistas do trabalho - a ética do rendimento, do esforço e profissionalismo - não passa de ideologias sofisticadas produzidas pelo sistema. Tal utopia não seria possível em um contexto "onde o trabalho não é mais a principal força produtiva e onde, por conseguinte, não há empregos permanentes suficientes para todo mundo" (GORZ, 2007, p.75). Haveria neste processo motivacional utópico uma racionalidade instrumental que controla ideologicamente este grupo de trabalhadores. Retoma-se a ética do trabalho, destruindo qualquer vínculo solidário que poderiam ligá-los aos menos privilegiados; convence-os de que trabalhando o máximo possível, meIhor servirãoaos

interesses da coletividade; classificam-nos por outras terminologias - como colaboradores - criando a ilusão de que o conflito e antagonismo existentes entre patrões e funcionários acabaram.

\section{CONSIDERAÇÕES FINAIS}

Vivenciamos uma era marcada pelas transformações na produção, nas relações de trabalho e no papel desempenhado pela atividade laboral como fonte de referência e identidade social. A precarização do emprego leva a um aumento da exclusão social, impõe diversas dificuldades às ações trabalhistas e questiona os referenciais que instituiram o trabalho como base da estrutura social. Observamos, com base nas orientações teóricas de Gorz $(2005,2007)$, que a discussão do tempo de trabalho aponta para o esgotamento do paradigma da produção.

A diminuição progressiva dos empregos agravou a desintegração da sociedade e tem obrigado os indivíduos a buscarem em outras esferas as fontes de identidade e pertencimento social, as possibilidades de desenvolvimento pessoal e um sentido que norteie sua existência. A alternativa proposta por Gorz para uma libertação individual se pauta na sociedade do tempo liberado. A emancipação dos indivíduos passaria pela liberação do trabalho a partir da redução da jornada diária que possibilitasse uma maior autonomia existencial. 0 desenvolvimento de outros centros de interesse e outras atividades para além de seu trabalho remunerado possibilitaria, na visão do autor, o desenvolvimento de uma visão multidimensional da existência individual e social.

Seja por meio de uma "renda de existência" ou de algum outro meio, devemos almejar esta autonomia para não esquecermos as diferenças entre a vida e o trabalho. Seria utópico acharmos que o capitalismo inquietar-se-ia com outra coisa que não seu lucro, mas não podemos ignorar que, no último século, ele passou por diversas crises e todas tinham em comum a superprodução. Cada período se caracteriza por um tipo de produção e é 
inegável a velocidade e intensidade da fabricação de informação no presente. Nesse sentido, seria ingênuo pensar que estamos livres de uma crise pelo fato de a produtividade estar pautada na imaterialidade.

As reflexões acerca dos sentidos e implicações das transformações no mundo do trabalho não se encerram aqui. É importante destacar que as perspectivas teóricas, aqui utilizadas para tentar compreender as modificações trabalhistas na contemporaneidade, são apenas algumas dentre uma infinidade existente. $O$ fundamental é que o trabalho permaneça como importante objeto de estudo entre as diferentes áreas e orientações. $O$ futuro da atividade laboral é incerto, mas é provável que, diante das limitações, riscos e contradições, outro mundo emirja deste processo de transição.

\section{REFERÊNCIAS BIBLIOGRÁFICAS}

CASTELLS, Manuel. A sociedade em rede. 4. ed. São Paulo: Paz e Terra, 1999. 617 p.

GORZ, André. Metamorfoses do trabalho: crítica da razão econômica. 2. ed. São Paulo: Annablume, 2007. $247 \mathrm{p}$.

O imaterial: conhecimento, valor e capital. São Paulo: Annablume, 2005. 106 p.

HARVEY, David. Condição pós-moderna: uma pesquisa sobre as origens da mudança cultural. 7. ed. São Paulo: Loyola, 1992. 349 p.

SENNETT, Richard. A corrosão do caráter. 13. ed. Rio de Janeiro: Record, 2008. 204 p.

TERRANOVA, Tiziana. Free Llabor: producing culture for the digital economy. Disponível em: <http:// www.electronicbookreview.com/thread/technocapitalism/voluntary>. Acesso em: 14 set. 2009. 